\author{
Людмила Кирова \\ Comenius University in Bratislava \\ lyudmila.kirova@gmail.com
}

\title{
СЪВМЕСТНА УПОТРЕБА НА КИРИЛИЦА И ЛАТИНИЦА В БЪЛГАРСКИ ТЕКСТ - ЗАЩО И КОГА
}

В тази работа предлагам резултатите от изследване върху употребата на латиница, което проучва български текстове, функциониращи в публичното комуникативно пространство. Моята цел беше да установя: Какви са обхватът и степента, до които стига явлението „сьвместна употреба на кирилица и латиница“" в българския език? Какви са факторите и движещите процеси, които налагат подобни употреби? В какви случаи се прилага съвместната употреба на кирилица и латиница в български текст и с каква цел? Какъв е характерът на тези употреби - доколко те са прояви на явления като билингвизма и диграфията?

В сферата на социолингвистиката явлението „употреба на кирилица и латиница“ в българския език засяга въпроси, свързани с билингвизма и диграфията. „Билингвални са тези индивиди и общности, които притежават способност да посрещат комуникативните нужди, както своите собствени, така и тези на обществото, при нормалното си функциониране на два или повече езика при взаимодействието си с други говорещи на някой от тези езици или на всичките“. [Mohanty 1994: 13]. В съвременните модерни общества нараства билингвизмът с английския език като последица не само и не толкова от пряко общуване между разноезични индивиди (напр., при работа в международни фирми, организации и институции), а като масивно индиректно въздействие чрез масовата култура и информационното доминиране (количество на информационните източници) на английския език. Социалният билингвизъм е тясно свързан с понятието езиков контакт, разбирано в тесен смисъл като ситуация на контакт, задължително свързана с двуезичие, и в по-широк - когато и без то да е налице, социални, политически, културни и други причини водят до процес на лексикално заемане (напр. настоящата ситуация в националната езикова общност).

Преминаването от една структурна езикова формация на друга в процеса на комуникацията се определя като превключване на кода [Виденов 
2000: 212]. Мисьлта плавно продължава, но с изразните средства на друг език, редуват се отрязъци, подчинени или прости изречения, оформени по граматичните правила на различни системи. При смесването на кодове в единия език се вмъкват елементи от друг, без те да променят основния характер на изказването. Предпочитанието на единия език пред друг е социално значимо, когато се извършва под въздействието на някой/и от факторите на комуникативната ситуация [Gumperz, Cook-Gumperz 1982: 19]. При това пасивната употреба на чуждия език също оказва влияние за акумулиране на езиков материал, правила и модели, разширяващи речевия репертоар. Диграфия представлява използването на две (или повече) графични системи за писане, за да се представят разновидности на един език“, т.е. това е различно графично предаване на даден език [Dale 1980].

Първите ми наблюдения върху проявите на билингвизъм и диграфия върху езика на носители на българския език са върху речта на компютърно базирани групи (КБГ): компютърджии, геймъри и чатъри [Кирова 2002]. Установих, че поради характера на заниманията си в рамките на групата членовете са принудени да използват специфична терминология и други названия от английския език. Вследствие на това проявяват частичен билингвизъм - предимно смесват кодовете, а не ги превключват координирано. Смесването не е неволно и произволно, а се осьществява по комуникативните норми на речевата общност, в която се реализира речевия акт. В крайна сметка КБГ създават в собствения си социолект разширено поле на употреба на стандарти от два езика и две графични системи - на българския и на английския език. Подобни процеси протичаха и протичат и в други социални групи по линия на други занимания, независимо непрофесионални или професионални, напр., спорт, музика, кино, бизнес, реклама, туризъм и пр. В тях са посети много от семената на интегрирането на чужди думи, словообразувателни модели и дискурсни практики, които покълват в речта на членовете им и впоследствие се разпространяват в публичното пространство.

Сегашното изследване, през 2017 г., не е ограничено върху езика на определени социални групи, а има за обект езикова продукция на носителите на съвременния български език въобще. Част от употребите обаче съвсем не са нови, а са използвани от определени професионални и социални общности в техните комуникативни практики. Днес обаче тези практики се популяризират и навлизат в ежедневието на всеки съвременен българин. Условията на глобална информационна среда диктуват редица избори, които имат прагматичен смисъл. Факторите, детерминиращи развитието на съвременната комуникация, са Глобализацията, Информационното общество и Визуалната култура. Ето и различни аспекти в действието на тези фактори, които имат решаваща роля за употребата на латиница в рамките на текст на кирилица. Глобализация: международни стандарти; глобално консуматорско общество; мобилно общество; масова култура без граници; Информационно общество: широко присъствие на науката и технологиите в ежедневието; глобални медии и социални мрежи; специализация на публиките - дискурс- 
ни общности; Визуална култура: визуалният знак - универсален символ; графичният образ като визуален символ.

Провеждането на международни стандарти е стара практика в областта на науката и техниката. Такива са например означенията на различни физични величини ( $\mathrm{G}$ - тегло, $\mathrm{m}$ - маса, $\mathrm{E}$ - енергия и пр.) и измерителни единици ( $\mathrm{V}$ - волт, $\mathrm{W}$ - ват и пр.). Биологията и медицината имат интернационални класификационни системи, базирани на латинския език. Днес, след падането на желязната завеса и в епохата на интернет, действа тенденция към интернационализация на терминологичните системи на основата главно на английския език. Това означава, че дефинирането на понятието за ново откритие или изобретение обикновено става първо в английския език или най-малкото чрез неговото посредничество в случай, че се е осъществило в другоезична страна. Английският език е основен език за международни комуникации и бизнес. Своя принос към навлизането на чужди названия и надписи в монолингвална среда дават и международният пазар и финансовите институции. Не е възможно в условията на глобално консуматорско общество да не възприемаме брандовете и продуктите заедно с тяхното оригинално обозначаване. Още повече, че независимо къде по света пътуваме, те имат еднакъв изглед. Развиват се също единни стандарти и названия, свързани със самите пътувания, настаняването и обслужването на съвременните мобилни хора. Унифициращо е също въздействието на масовата култура, която е силно американизирана. По линия на браншове като музиката, рекламата, киното и др. съвременната аудио, визуална и мултимедийна среда е доминирана от послания на английски език в устна и писмена форма. Всеки, който се бори за нелокална, а глобална публика, предпочита да създава и/или разпространява произведенията си на този език.

На съвременния етап на развитие науката и технологиите присъстват в ежедневието ни във все по-висока степен. Необходимо е да боравим с техните продукти, да познаваме редица стандарти и специални названия, за да бъдем активни членове на Информационното общество. Съобразяването със стандарти, които имат локална задължителност и допустимост, е отстыпило пред толерирането на такива интеракции, които осигуряват разбирането чрез прилагане на глобални правила и универсални модели. А еднаквите начини на действие и мислене придават сходни социални параметри и сближават речта даже на хора, говорещи различни езици. Глобалните правила и универсалните модели се прилагат спрямо определени публики в определени условия. Създават се дискурсни общности. Ефектът на глобалните медии и социалните мрежи е, че формират у нас определен тип комуникативни практики. Така напр., жанровете на компютьрно опосредстваната комуникация (КОК) притежават характеристики, които съвместяват особености на спонтанната устна и писмена реч; на два езика и на две графични системи; на буквени и на прагматични знаци и др. Те трябва да се усвояват и интерпретират само като единство на текста с неговата употреба. Налагането на чисто лингвистични оценки спрямо силно прагматични жанрове е проява на отричане на 
природата на езика - да служи на човека да усвоява, изразява и управлява действителността, която възприема. Невъзможно е езикът да остава с непроменени характеристики, когато светът драстично се променя.

Човечеството се придвижва към все по-широка употреба на визуални знаци (идеограми и пиктограми) в ролята на универсален език. Указателните знаци от летищата и туристическите центрове днес бурно са се развили, а съществуват и огромни системи от икони, чрез които управляваме компютрите и смартфоните си. Буквите се явяват знаци на звуковете и формирани в думи се явяват знаци на човешкия език. В съвременността обаче на графичния образ на думата се придава и допълнително значение. То може да бъде прагматично (напр., запазена марка, принадлежност към определена система на специално знание) или естетическо (определено въздействие).

В този смисъл първият извод от изследването е, че употребата на латиницата в текст на кирилица е маркер на специално знание. Освен това при оценката на отделните употреби трябва да се вземат предвид и следните противопоставяния - дали вариантьт с латиница се явява:

- един от повече варианти - единствен вариант- липсва вариант в българския език

- стандарт - субстандарт

- при съвместна употреба на ниво изречение - на фраза - на дума

Да разгледаме следните примери: 1. производство на $\boldsymbol{C a C}_{2}$ [производство на калциев карбид, $\mathrm{CaC}_{2}$-Produktion]. Тук първият вариант е терминологичен и включва химическа формула, изписана с латиница, а в квадратните скоби е даден описателен вариант на терминологичното название, както и съответният термин на немски, който включва същата формула. 2. B CAD/JPY щуе е по-голяма печалбата. [Canadian dollar / Japanese yen $=88.3307051$ ] - Този пример представлява употреба на латница във функцията на международен терминологичен стандарт за отбелязване на валути. 3. Смартфонът ОпеРlus5 е оборудван с 5,5-инчов дисплей с резолюичя 1920х1080 пиксела, 6 или $8 \boldsymbol{G B}$ оперативна памет, 64 или 128 GB вградена памет и мощцна 3300 m $\boldsymbol{A h}$ батерия. Основната камера е двойна: широкоъгълен модул с фотосензор Sony IMX 398* и резолющчия 16 MP и телефото модул със сензор Sопу $\boldsymbol{I M X} 350$ с резолюичя 20 MP. - Тук латиницата е приложена отново като международен стандарт, но този път технологичен - маркира универсално разпознаваеми имена на класове продукти, които ориентират за техни характиристики. *IMX е вид CMOS сензор за изображения, а CMOS (complementary metal-oxide semiconductor) image sensor означава сензор за изображения от вида “допълващи метало-оксидни полупроводници“, т.е. - абревиатурата маркира [вид технология] ${ }^{1}$. От примерите се вижда, че латиницата винаги маркира, че става въпрос за дума, която е знак на специално знание. При

${ }^{1}$ Абревиатурата маркира, че названието е знак от специално знание. Ето защо, когато се има предвид определена технология, задължително се пише GSM, а когато значението е предметно ('телефон') може да се използва и вариантьт джиесем. 
това вариантите са стандартни, но този стандарт е глобален, а не локален, като често е единственият вариант в българския език. Специалните означения не винаги се знаят от всички, но винаги може да се направи справка за тяхното съдържание.

Нека сега разгледаме типичните случаи на употреба на латиница в български текст:

\section{I. Дефиниране:}

Точното определяне на значението на термин в българския език се извършва като българското название е съпроводено от международно приетото название на термина, обикновено дадено в скоби. Това е практика, позната например от медицината и биологията: 4. Белият щзьркел (Ciconia ciconia) е вид едра птица, представител на семейство Щъркелови.; 5. Предложението принадлежи на Рамковата конвенция по въпросите на климатичните промени към ООН (United Nations Framework Convention on Climate Change, UNFCCC). Този начин се налага с цел въвеждане и утвърждаване на термина в българския език, както и на неговото съкратено название - абревиатурата (която е мотивирана от съставно название извън българския език). В редица случаи това се налага и поради факта, че на български има няколко различни названия на термина/професионализма поради различен превод $(6,7)$. В превода също така може да лежи различна образна метафора (8): 6. отметки, бележки са различни названия на функцията bookmarks, която отделни преводачи на платформата с отворен код Linux предложиха при нейната локализация на български език. 7. Ако cme c Android meлефон или таблет, отидете в „,Настройки за Google (Google Settings) “, натиснете „местоположение (Location) “ и натиснете на „Позиция (Location)“, ако не е в зелено (под „Режим“ в дясно трябва да пише „Само GPS“ ако Позиция е натисната). - Тъй като различните производители на телефони може да имат различен превод на дадена функция за управление, обясняващият я изписва и на английски. 8. Ефект педали (или Джаз кутии (Stomp bох)) са ефект елементи. Поместени в малко метално шаси те се използват главно от китаристи, но понякога и от музиканти, свирещуи на други струнни инструменти.

Следващият пример показва, че когато има съвпадение в облика на букви от кирилицата и латиницата и това би затруднило разбирането на съобщението, специално се указва, че изписаното е на латиница, за да се подчертае и нейната функция като маркер на специално знание. 9. Концентрацията на твърди частици във въздуха по-малки от 2,5 микрона в диаметър, или т.нар PМ 2,5 (латиница - б.ред.), достига в южната част на Пекин 900 микрограма на кубически метьр.

\section{II. Детерминиране}

В съвременността е от изключителна важност точното отнасяне на дадена информация към обект от действителността. Нужен ни е ключ, за да 
можем от морето информация да извадим нужните ни данни. В този смисъл точното назоваване осигурява точно разпознаване и възможности за допълнителна информация.

Начините на детерминиране могат да бъдат различни:

- посочване на названието в оригинал - Това означава, че ако информацията от дадена статия ви е недостатъчна, винаги можете да потърсите повече по выпроса с ключова дума оргиналното название: 10. Cucmeмama Facs помага да различим сигналите на лицето.

- цитиране на източник - Тук допълнителните данни идват чрез проверка в цитирания източник: 11. ...това сочат данните на проучването Huawei Summer Barometer 2017 сред 12 европейски страни.

- запазена марка - Тук водеща причина за употребата на оригиналното изписване на името на даден продукт или фирма е нейното разпознаване в глобален мащаб. Тъй като това явление оказа съществено въздействие за установяването в българския език на съществени изменения в оформянето на именната група, ще се спрем на този въпрос по-подробно.

През последните около 25 години все по-често в българския език се употребяват ендоцентрични детерминативни номинативни конструкции с дясна опора. Пример 12 е типична българска именна група със съгласувано определение в препозиция и с приложение: Настолният компютьр іMac - Този ред на думите в именната група подчертава идентифициращата функция на названието. Сега да разгледаме пример 13, където значението е сходно, но не аналогично, а конструкцията е с предпоставени несьгласувани определения, свързани верижно чрез прилагане: Apple iMac настолни компютри - Става въпрос за множество идентични продукти с общо име (дадена марка, серия, клас) и дадени качества - функцията на названието е характеризираща, като има имплицирани категории: [фирма] Apple [марка продукти] iMac настолни компютри. Този тип свързване е иновация в българския език и се разви под влияние на английския език, за който е типичен. Неговите предимства са няколко и първото от тях е, че:

- дава възможност за имплициране, а това, което се имплицира е вид/клас в рамките на родова категория: 14. iPhone бие всички Android модели, счита създателят на Geekbench. Apple е по-добре позиционирана от свочте Android конкуренти относно бъдещето на мобилните технологии. В този пример Android модели маркира имплицирано знание и означава 'модели телефони с мобилна операционна система Android'.

В примера се съдържа и втората възможност, която дава този тип конструкция и тя е:

- прототипно назоваване - Нещо се ражда като продукт със свое название (в случая - операционната система Android), но скоро става множество от нови, развити на негова основа продукти. Всички техни характеристики най-добре могат да бъдат маркирани чрез името на първоначалния продукт, напр.: 15. Linux-базирани платформи с отворен код. 
Така стигаме до предимството на синтактично компресирания вид на една подобна конструкция. Такъв израз особено се предпочита при обяви, заглавия и в дискурси, които изискват максимална информативност в малък обем, който се постига с верижния изглед:

- последователно свързване чрез прилагане (concatenation) $\rightarrow$ верижен изглед: 16. 100 броя full HD екшън камери.

- възможността за незабавна употреба на чужд знак в текст на български език - Това е друго предимство на детерминативните конструкции. Чужди знаци могат да участват в номинация в българска реч чрез новия зает словообразувателен модел, стига да имат репрезентант в съзнанието на говорещия: 17: Пътеката до фара се е изпънала между надрасканите с wannabe графити стени и пляскащите в прибоя вълни.; 18. Подготовка за изпит I - TODO списък - скелети на проектите. Следователно конструкцията се явява механизъм за интеграция на чужди думи, чрез който се осъществява процесът на адаптация от вмъкване към заемане.

- прагматични причини за заемане. Зададох си въпроса защо големи зали от типа Арена се наричат Арена Бургас, Арена Армееи, а напоследък чета: 19 .Откриват ,Фестивална - Asics Arena' през септември. При откриването на обновената зала беше обявено, че ...съоръжението вече ще носи името „Asics Арена“. След проучване установих, че Asics е фирма за спортни обувки, която се е ангажирала да спонсорира обновяването и поддръжката за 6 години на бившата зала „Фестивална“ (срещу вечната реклама името ѝ да се произнася и изписва всеки път, когато стане дума за залата). Т.е. много често рекламни цели стоят зад дадена форма на изписване на определено име.

Тук бих искала да повдигна и друг въпрос. Вариантите на изписване често са зависими и от сферата на функциониране, стила и доколко е познато наименованието. Така например се оказва, че названието на фирмата Lidl, изписано на латиница, е най-приемливият и широко употребяван вариант. 20. Фотошоп-коректността предизвика PR-криза за Lidl. (webcafe. $\mathrm{bg})^{2}$ На собствената си страница българският клон на фирмата се представя като Лидл България, което е неправилна форма с оглед на българското произнасяне и правопис. Такива употреби обаче се прехвърлят и в други издания: 21. “Лидл България" щее продава продукти, изработени по стари семейни рецепти. (в-к „Капитал“). Правилната форма Лидъл, която е нормална за всеки българин, не се толерира от фирмата, тъй като се отдалечава от оригинала. По тази причина тя остава затворена в междуличностната комуникация: 22. Незнам защо си купувате тези от Лидъл (форум); 23. Лидълските [сгъваеми триони] са много добри, аз ги ползвам при правенето на ножове. Иначе любими са ми трионите на Fiskars. (коментари в Youtube

${ }^{2}$ Всички примери са с оригинален правопис. Макар да е кирилизирано, названието Фоmошоп-коректността, написано с дефис, е неправилно - би трябвало да е написано раздел-

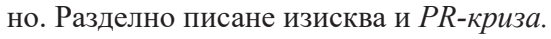


под любителски демонстрационен клип за сгъваеми триони). При търсене в Google, тъй като търсачката притежава алгоритми за транслитерация, формите с вмъкнато в се тълкуват като грешка и са изместени от вариантите Lidl и Лидл, които се свързват с названието на фирмата. За съжаление в практиката и при фирмите е трудно да се преборим така, както го направихме пред EC в езиковия спор за названието „евро“ и за комуникацията на български и употребата на кирилица в официални документи на ЕС. След приемането на България в ЕС Европейската централна банка поиска наименованието на общата европейска валута на български език да бъде „еуро“. Българската страна обаче защити позицията, че правилното изписване е „евро“. Тя се позова на европейските документи, в които е записано, че названието на валутата „се изписва еднакво във всички държави членки, но отчитайки особеностите на всички азбуки“, а също и на договора за присъединяването на България, където валутата на ЕС в текста на български език фигурира като „евро“. [Dariknews.bg 2007] През 2012 след писмо на българския евродепутат Ивайло Калфин до тогавашния председател на Европейския парламент Мартин Шулц службите на парламента предприеха адаптиране на сложната електронна система за създаване на документи към кирилските букви, като този процес отне повече от година. В резултат Европейският парламент започна да използва кирилица в официалните си документи и комуникация на български език, а българският преводачески отдел на парламента транскрибира небългарските имена в съответствие с правилата, изготвени от Българската академия на науките. [Technews.bg 2013]

\section{III. Цитиране}

Установих няколко случая, които могат да бъдат определени като цитиране и мотивират употребата на оригиналното название и изписване:

- цитиране за запазване на мотивиращия образ: 24. [...] твърди, че се появяват нови форми на „, четене“, при които потребителите „пробягват “ (power browse) хоризонтално през заглавия, съдържания и резюмета, търсейки бързи резултати.

- цитиране при проблеми с точността на превода: 25. [...] но и една заредена с положителен потенциал тема - well-being - една нова дисциплина в психологията, открита от американския учен Ед Динър.

- цитиране с цел коментар/оценка: 26. Едни пък са превели старателно името на FB страничката си ,,My Human Design“ ей така : „Моят Хюман Дизайн“. - Тук всъщност е подложена на критика безсмислената кирилизация, която по никакъв начин не помага названието да стане по-прозрачно за читатели, които не са билингви.

- цитиране на машинни съобщения: 27. След като натисна бутона „ОK“ в прозореиа Go to, ми дава съобщение Reference is not valid. 28. На мен ораколь $m^{3}$ [програма за забавни предсказания] ми предсказа , dream wedding “.

${ }^{3}$ Изписването ораколът вм. оракулът е приложение на разпространената в социалните мрежи дискурсна практика „стилизация на неграмотно говорене“, която е съзнателно търсен 


\section{IV. Операционален език}

Така съм нарекла случаи, при които речевата дейност е обвързана с друга дейност. Употребата на изписване с латиница е свързана с определени конвенции. Най-често операционален език срещаме в обяснителни текстове как се изпълнява определено действие, което съответства на функция, заложена в технологично устройство. Интересното е, че в тези случаи могат да се редуват варианти, които са в рамките на стандарта (Shift + F5, \#tempuswini) с варианти, които са субстандартни $(\boldsymbol{C P U} \boldsymbol{U}$ mo $<$ central processing unit, computer processor, Bootcamp-ския). Особено интересен е пример 32, в който варианти с латиница в ролята на глобален стандарт (Windows 7, BootCAmp) се редуват с варианти на кирилица - локален стандарт и субстандартни варианти (Уиндоус, Уина, Маковския) и смесени субстандартни варианти (Bootcaтр-ския). 29. Изключвам кеша на $\boldsymbol{C P U \_ m o ~ и ~ с к и п в а м ~ в и н б о з а ~ с ~ S h i f t ~}$ +F5. 30. Клипвам е един вариант на ,стрелвам“-затваряне след позвъняване. От СLIP - наименованието на услугата, която представлява. 31. Супер атмосфера при супер хора със супер вино \#tетриswini. 32. Тръгнах да инсталирам Windows 7 с ВоотCAтр на компа на мой приятел, просто му трябва и Уиндоус, та както и да е тръгна инсталаџията на Уиндоуса и дисковете бяха 3 - Маковския, Воотсатр-ския и един малък 200 МГ, но понеже си говорехме и аз не внимавах, дадох Уина да се инсталира на 200 МГ диск, след което се усетих и спрях инсталацията.

\section{V. Превключване и смесване на кодове}

Превключването на кода е резултат от билингвизъм и се среща все по-често за разлика от предходни изследвания, където съм установила, че най-често е в позиции, които са под прагматичен натиск от технологичен характер в условията на КОК. Това е така, защото понастоящем платформите, върху които се осъществява комуникацията във виртуална среда, са достъпни на български език. Днес превключването се осъществява или поради технологично-дискурсен натиск в определени позиции на платформата или като собствен избор на пишещия, т.е. в свободни позиции. Широко е застъпено в международни социални мрежи, напр., Facebook.

- превключване поради смяна на търсения ефект от изказването: 33. GB Sushi heaven (+ снимка от фестивал на суши $)^{4}$. 34. DI with ZT. on a Bulgarian party today on the board of Danube with the folklore singers Elitca Todorova. Thank you for the organization DS and LR! (+ снимка на пишещата и тагнатото лице, заедно с певицата).

- превключване на езиковия код, повлияно от комуникативните норми на жанра и социалната група. В статия, статус, пост, коментар, чат,

ефект с цел пародиране на реалната неграмотност. Подобни са и примери 35 и 36 , където неправилностите са спрямо английския език.

${ }^{4}$ Началните абревиатури в примерите представляват съкращения на имената на говорещите с цел запазване на анонимността. В скобите е изяснено съдържанието на съпровождащ визуален материал, което е съществено за цялостното въздействие на изказването. 
то може да се появи с оглед социалната група и функцията, която изпълнява - може да бъде както с информативна функция, така и с функция солидаризиране с групата, както и за забавление. Обикновено солидаризирането и забавлението вървят ръка за ръка в социалните мрежи. Те са типична комуникативна норма и широко разпространените дискурсни практики ги толерират. 35. ако не си го гледал, dо ееet (Facebook)

- превключване поради смяна на темата: Напр. след изказвания на български, говореща включва английско изказване клише, свързано с темата игри. 36. BD EXIT - lets da game begin - with TI and TJ.

- Смесването на кодове обикновено се проявява като начин за адаптация на заемки. 37. И аз съм grammar nazi, че даже членувам и в генералния щзаб на grammar nazi-mama. (Facebook)

Изводът от проучването върху превключването и смесването на кодове потвърждава, че е налице увеличение на съвременните дискурсни общности с разширено поле на употреба на варианти от два езика и две графични системи. Те развиват свои дискурсни практики. В този смисъл се осыществява специализация на публиките, които се формират като дискурсни общности. Някои от тези практики са по-познати в публичното пространство, други са по-тясно употребими в рамките на определени професионални и социални групи.

\section{VI. Стилистично средство}

Някои от прилаганите дискурсни практики се базират на използването на чуждоезикови елементи, които задействат специфична експресия, напр.:

- асоциации и метафори: 38. Палци горе, шоуто трябва да продължи, поне докато Валери Симеонов не тръгне на тихоносния си winter edition поход към Банско. “ 39. В „Big Brother „Most wanted“ България тьрси freak [...] Искам да замествам ,, wanted “ c „, wasted“, но няма да го направя.

- езикова игра:

40. Каква е тайната на малиновото вино? - Не знам. Иди я raspberry. Разбирането при подобни езикови игри е невъзможно без билингвизъм.

\section{VII. Паралелен двуезичен текст}

Като паралелен двуезичен текст могат да бъдат издавани документи, списания, книги (предимно поезия), но най-разпространеното приложение е под формата на ресторантско меню. Коректното използване изисква доброто познаване не само на двата езика, но и на специфичната терминология при ястията и начините на приготвяне. В противен случай резултатите са езикови гафове:

41. Топъл Хляб / Worm Bred 


\section{Диграфия}

Както е известно един от маркерите на комуникацията във виртуалното пространство в неговата българска част в миналото беше писането на български език като се използват латински букви и някои цифри, т.е. т.нар. шльокавица. Това се налагаше в зората на развитие на интернет, когато локализацията на платформи и софтуерни продукти на български още не беше осъществена в необходимата степен и срещахме затруднения да използваме кирилицата повсеместно. Днес подобни пречки са преодолени.

Освен това характерна нагласа за съвременното българско общество е негативното отношение към употребата на шльокавица. Почти всички български сайтове, където се обменят коментари, предупреждават, че написани по този начин постове и коментари ще бъдат изтривани от модераторите. Пример за широка кампания срещу такова писане е издаването на романа „Под игото“ на шльокавица. Това може да изглежда парадоксално, но публикацията е аргументирана така: 42. „Под игото излиза на ильокавицуа за 24 май. Издателство Жанет 45 отпечатва романа на тази абсурдна писменост, за да покаже колко голяма заплаха е тя за езика и културата ни.“" Всъщност акцията е психологически обоснована. Всеки българин, който разтвори книгата и се опита да прочете част по-дълга от един абзац, се убеждава, че да се чете текст, написан по този начин, е мъчително. Примамката за читателя да се подложи на този експеримент е наградата от две български книги, които той получава за всеки закупен екземпляр от изданието на шльокавица.

Така основните причини за изтласкването на това явление са:

- отсъствие на технологична зависимост

- отрицателни нагласи към практиката ,употреба на шльокавица”

- За съжаление в противоположна посока действат два други фактора:

\section{- финансови съображения - таксуване на SMS}

Може би не знаете това, но „кратките съобщения (SMS) излизат тройно по-скъпо, ако са написани на български с кирилица в сравнение с тези, изпратени на език с латинска азбука или с български думи, транскрибирани с латински букви“. Лимитът за обем на кратко съобщение е 160 символа на латиница. Ако въвежданото съобщение е на официалния език на страната - българския, съответно на кирилица, лимитът е 70 знака. [Захариева 2017]. Причината е, че има международни стандарти, според които знаците на латиницата са основни - таксуват се 7 бита, а другите азбуки се таксуват като 16 бита. IT специалистьт Марио Паунов обяснява това нагледно: „Есемесите се кодират през т.нар. Уникод. Представи си този Уникод като една таблица, като първите редове от нея са ти буквите на латиница, като следващите трябва да бъдат преведени до символи от първото ниво“. [Банкова 2017].

Изнесените факти са определено пречка в използването на кирилица при SMS комуникацията, макар с разпространението на смартфоните, посто- 
янният достьп до интернет и един куп приложения за общуване намаляват хората, които пишат съобщения през GSM мрежата.

\section{- липса на клавиатура на кирилица}

Тази причина действаше при мобилните телефони от поколението преди тъчскрийн екраните. Тогава хората боравеха с латинските букви, които имаха върху бутоните на телефоните си. Просто ги мързеше да запомнят разположението на кирилицата - коя буква на кой бутон се намира. Други още тогава бяха наясно с по-скъпото таксуване. Днес липсата на клавиатура на кирилица се оказва основателна причина да се използва латиница главно тогава, когато човек е в чужбина и не разполага с възможност да оборудва компютъра от който пише с такава - особено когато компютърът не е личен. Често във форумите и социалните мрежи хора в такова положение специално обясняват това и искат извинение, че затрудняват останалите да четат коментарите им в този вид. ${ }^{5}$

Може да се заключи, че употребата на диграфия в българския език днес е ограничена до специални случаи. ${ }^{6}$ Това става под формата на явлението „писане на шльокавица”, което намалява все повече, свивайки се основно до случаи на прагматична принуда.

\section{Изводи}

Генералният извод от изследването е, че съвместната употреба на латиница и кирилица се явява резултат от разширяването на билингвизма с английския език. Все повече български граждани разполагат с разширено поле на употреба на варианти от два езика и две графични системи.

На второ място, прилагането на латиницата е стыпка към универсалния език на образния знак, тъй като нейният графичен образ действа като визуален символ на прагматично знание.

\section{Библиография}

Банкова Е. (2017), Защуо sms-и на кирилица излизат по-скъпо от тези на латиница? Dariknews. bg, 10.02.2017, https://dariknews.bg/novini/bylgariia/zashto-sms-i-na-kirilica-izlizat-po-skypoot-tezi-na-latinica-video-2002751 (8.02.2018).

Виденов М. (2000), Увод в соииолингвистиката, София.

Захариева М. (2017), SMS-ъm на кирилица - тройно по-скъn! Дискриминация ли e?, Dnes.bg, 31.01.2017, https://www.dnes.bg/obshtestvo/2017/01/31/sms-yt-na-kirilica-troino-po-skypdiskriminaciia-li-e.330432 (8.02.2018).

\footnotetext{
${ }_{5}^{5}$ Могат да се използват конвертори, които трансформират написаното от латинската клавиатура в текст на кирилица, напр., http://5ko.free.fr/bg/cyr.html, https://2cyr.com/ (9.02.2018).

${ }^{6}$ Тук трябва да прибавим и транслитерацията, която в България засяга главно предаването на имена и географски названия (вж. Закон за транслитерацията, ДВ, бр. 19, 13.03.2009). За сравнение в Япония, Китай, Южна Корея спомагателното писане с латиница (романизация) е стандартизирано и децата го изучават в училище.
} 
Кирова Л. (2002), Билингвизъм и диграфия в речта на българските геймъри, [в:] Проблеми на соииолингвистиката, t. VII, Билингвизъм и диглосия - съвременни проблеми, Международно социолингвистическо дружество, София, Делфи, 2002, с. 100-110. Също: LiterNet, 11.08.2001, № 8 (21), http://www.liternet.bg/publish3/lkirova/gamers.htm, (8.02.2018).

Dale, I. H. (1980), „Digraphia”, „International Journal of the Sociology of Language”, vol. 26, p. 5-14. Published Online: 2009-10-07|DOI: https://doi.org/10.1515/ijsl.1980.26.5.

Dariknews.bg (2007), Решен е проблемът с изписването на еиго на български, 18.10.2007, https://dariknews.bg/novini/sviat/reshen-e-problemyt-s-izpisvaneto-na-euro-na-bylgarski-189825 (9.02.2018).

Gumperz J., Cook-Gumperz J. (1982) Introduction, [in:] J. Gumperz (ed.), Language and Social Identity, Cambridge.

Mohanty A. (1994), Bilingualism in a Multilingual Society, Mysore, Central Institute of Indian Languages.

Technews.bg (2013), Европарламентът ще пише на български с кирилица, 7.08.2013, https:// technews.bg/article-53738.html (9.02.2018).

\section{Людмила Кирова}

\section{JOINT USE OF CYRILLIC AND LATIN ALPHABET IN BULGARIAN TEXT - WHY AND WHEN}

\section{(Summary)}

The author investigates in which cases the joint use of Cyrillic and Latin is used in Bulgarian text and for what purpose: definition, determination, citation, operative language, code-switching and code-blending, use as a stylistic tool and parallel bilingual text. The nature of these uses is described and the extent to which they are manifestations of phenomena such as bilingualism and digraphia. The general conclusion is that the joint use of Latin and Cyrillic is the result of the expansion of bilingualism with English. More and more Bulgarian citizens have an extended field of use of variants of two languages and two graphical systems. Secondly, the application of the Latin alphabet is a step towards the universal language of the image, since its graphic image acts as a visual symbol of pragmatic knowledge.

Key words: Latin as an international alphabet, bilingualism, code-switching and codeblending, digraphia, transliteration of the Bulgarian letters with Latin ones 